\title{
Portal Vein Embolization (PVE) Versus PVE with Haematopoietic Stem Cell Application in Patients with Primarily Non-resectable Colorectal Liver Metastases
}

\author{
VLADISLAV TRESKA ${ }^{1}$, JAKUB FICHTL ${ }^{1}$, JAROSLAV LUDVIK ${ }^{2}$, JAN BRUHA ${ }^{1}$, \\ VACLAV LISKA $^{1}$, INKA TRESKOVA ${ }^{1}$, RADEK KUCERA ${ }^{3}$, ONDREJ TOPOLCAN ${ }^{3}$, \\ DANIEL LYSAK ${ }^{4}$, TOMAS SKALICKY ${ }^{1}$ and JIRI FERDA ${ }^{2}$ \\ Departments of ${ }^{1}$ Surgery, ${ }^{2}$ Radiology, ${ }^{3}$ Immunochemistry, and ${ }^{4}$ Hemato-oncology, \\ University Hospital, Faculty of Medicine, Pilsen, Czech Republic
}

\begin{abstract}
Background: Portal vein embolization (PVE) and $P V E$ with autologous mesenchymal stem cell application (PVE-MSC) increases future liver remnant volume (FLRV). The aim of this study was to compare both methods from the aspect of FLRV growth, progression of colorectal liver metastases (CLM), CLM resectability and long-term results. Patients and Methods: Fifty-five patients with CLM and insufficient FLRV were included in the study. FLVR growth and CLM volume were evaluated using computed tomography. Liver resection was performed in patients with FLVR $>30 \%$ of total liver volume. Results: In the PVE $(N=27)$ group, FLRV growth was observed in 23 patients (85.2\%) and in $100 \%$ of patients in the PVE-MSC $(N=28)$ group $(p<0.05)$. The rapidity of FLRV and CLM growth did not differ between groups. $R 0$ resection was performed in 14 (51.8\%) and 24 (85.7\%) patients from the PVE and PVEMSC ( $p<0.02)$ groups, respectively. The 3-year overall and progression-free survival rates were $85.75 \%$ and $9.3 \%$ in the $P V E$ group and $68.7 \%$ and $17.1 \%$ in the PVE-MSC group, respectively ( $p<0.67$ and $p<0.84$, respectively). Conclusion: $P V E-M S C$ allows for more effective growth of FLRV and resectability of CLM compared to PVE. The two methods do not differ in their long-term results.
\end{abstract}

Liver resection is the only method of multimodal therapy that offers patients with colorectal liver metastases (CLM) a chance of long-term survival $(1,2)$. Unfortunately, fewer

Correspondence to: Vladislav Treska, MD, Ph.D., Professor of Surgery, Department of Surgery, University Hospital, School of Medicine, Alej Svobody 80, 304609 Pilsen, Czech Republic. Tel: +420 3771042701, e-mail: treska@fnplzen.cz

Key Words: Colorectal liver metastases, portal vein embolization, stem cells, future liver remnant volume. than $30 \%$ of patients diagnosed with CLM are primarily operable. One of the principal reasons for CLM nonresectability is the low future liver remnant volume (FLRV). Currently, several methods exist that increase FLRV and, thus, secondary resectability of CLM. Our Department of Surgery uses two procedures: portal vein embolization (PVE), and PVE with autologous mesenchymal stem cell (MSC) application (3). The aim of this study was to compare both methods from the aspect of the rate of FLRV growth, increase in CLM volume and long-term treatment results.

\section{Patients and Methods}

A retrospective study was conducted between 2010 and 2017 involving 55 consecutive patients with insufficient FLRV out of a total of 483 patients undergoing surgery for CLM. Twenty-seven patients (19 men and eight women) were in the PVE group and 28 in the PVE-MSC group (22 men and six women). The average age of patients in the PVE group was $62.1 \pm 7.3$ years and in the PVEMSC group was $60.9 \pm 9.4$ years (non-significantly different). In all patients, the CLM were located in the right liver lobe. When the CLM were also located in the left liver lobe, our first step was to use metastasectomy or radiofrequency ablation to clear the left liver lobe followed by PVE or PVE-MSC in the second phase. The principal inclusion criteria were the absence of extra-hepatic metastases (verified by using hybrid positron-emission and computed tomography) and patient informed consent to participation in the trial. The study was performed in accordance with the ethical standards of the Institutional Committee and with the Helsinki Declaration. All patients signed informed consent forms.

In both groups of patients, the branch of the portal vein on the side of the CLM was embolised using a mixture of Histoacryl (BBraun, Tuttlingen, Germany) and Lipiodol (Guerbet, Rennes, France) at a ratio of 1:10.

In the first 10 patients from the PVE-MSC group, the source of MSCs was peripheral blood stem cells collected by peripheral blood apheresis. Patients underwent stimulation using granulocyte colonystimulating factor (Neupogen; Amgen Europe B.V., Breda, the 
Netherlands) at a dose of $10 \mu \mathrm{g} / \mathrm{kg} / \mathrm{day}$ administered subcutaneously as a single dose for 4 days before collection. From the fourth day of Neupogen application, circulating stem cells were monitored in the peripheral blood (detection of $\mathrm{CD} 34^{+}, \mathrm{CD} 133^{+}$cells using flow cytometry). On the fifth day after starting Neupogen, a single largevolume leukapheresis was performed on a Cobe Spectra (Caridian BCT, Lakewood, CO, USA) continuous blood-flow cell separator using the program for mononuclear leukocyte apheresis (MNC program, software version 6.1; Gambro BCT,Lakewood, CO, USA) via a dialysis catheter inserted into the femoral vein. A total of approximatety three patient blood volumes were processed and the anticoagulant used was citrate and citric acid based (ACD-A; Baxter, Deerfield, IL, USA) at a ratio of 1:12-1:14 to whole blood. All patients were administered calcium supplementation into the return intravenous line (fractioned, total dose of $10-20 \mathrm{ml}$ of $\mathrm{CaCl}_{2}$ ) in order to prevent citrate toxicity. The product collected this way was analysed and basic quality parameters were determined: volume concentration and absolute $\mathrm{CD}_{4} 4^{+}$and $\mathrm{CD} 33^{+}$cell count, erythrocyte and thrombocyte content, viability of $\mathrm{CD}_{3} 4^{+}$and $\mathrm{CD} 133^{+}$cells, and sterility. Sampling for these tests was performed within the closed system. Before mobilisation, all patients underwent testing for blood transmitted diseases (human immunodeficiency virus, hepatitis B virus, hepatitis C virus, syphilis). The product thus acquired did not undergo any further manipulation and was stored until the next day at a temperature of $2-8^{\circ} \mathrm{C}$ under continuous monitoring of storage conditions. The following day, the product was delivered from the laboratory for implantation in the operating room under radiological control via an alternating incision in the right lower abdomen into the ileocolic vein. total of $100 \mathrm{ml}$ of the product containing $1 \times 10^{7}$ MSCs was applied. PVE was performed using the transparietal approach 1 day before leukapheresis.

In the last 18 patients, MSC collected from bone marrow were used, a less-time consuming approach given that both collection and application take place at the same time. One day before collection, patients underwent PVE on the CLM side as described above. Under general anaesthesia, $300 \mathrm{ml}$ of aspirate was collected from the posterior iliac crest into an anticoagulant solution. This aspirate was subsequently centrifuged in the operating room and processed a using special device (Res-Q 60 BMC System; ThermoGenesis Corp., Ranco Cordova, CO, USA). A product corresponding to onetenth of the original aspirate volume was acquired in this way. This product contained a large amount of MSCs (CD133+ and CD34+). However, it also contained other blood elements. The product was then applied via an incision in the right lower abdomen into a branch of the ileocolic vein via a catheter under radiological control and then into the contralateral branch of the portal vein.

The growth of the contralateral liver lobe was monitored in both groups using computed tomographic liver volumetry at weekly intervals for a period of 3 weeks. Optimal FLVR was considered to be a volume $>25-30 \%$ of the total liver volume. In patients with damaged liver parenchyma, this volume had to be $>40 \%$.

Statistical analysis. Statistical analysis was performed using SAS software (SAS Institute Inc., Cary, NC, USA). Basic statistical data were calculated for the measured parameters for the sample as a whole, as well as for individual groups. The differences between the studied parameters were tested using the paired sign test. The relationships between the variables were studied using Spearman's correlation coefficient. The analysis of overalls survival (OS) and progression-free survival (PFS) was based on Kaplan-Meier survival curves. The impact of individual factors was tested using the log-rank test, the Gehan-Wilcoxon test and the Cox regression model. Statistical significance was set at alpha $=5 \%$.

\section{Results}

In the PVE group, optimal FLRV growth occurred in 23 patients $(85.2 \%)$ and in the PVE-MSC group it occurred in all patients $(100 \%)$ at 3 weeks $(p<0.05)$. The rate of FLRV growth did not differ between the two groups of patients (Figure 1). Radical R0 resection was performed in 14 (51.8\%) and $24(85.7 \%)$ patients from the PVE and PVE-MSC groups, respectively $(p<0.02)$. We were unable to perform liver resection due to CLM volume or increase in number in nine patients $(33.3 \%)$ in the PVE group and four patients $(14.3 \%)$ in the PVE-MSC group $(p>0.05)$. From the aspect of CLM volume increase before the procedure and 3 weeks after, there was no significant difference between the groups (Figure 2). The growth of CLM volume over time was significant in the PVE-MSC group $(p<0.0001)$. We did not find any significant difference in regard to OS and PFS between patient groups (Figures 3 and 4). We compared the results of OS and PFS in these patients with that of the whole group of patients undergoing surgery for CLM during the same period (Figures 5 and 6), n (\%) However, the OS in these two groups did not differ compared to the whole group of patients.

\section{Discussion}

Colorectal cancer is the third most frequent malignant tumour in our population. Thirty-five to $55 \%$ of patients develop CLM at different intervals of time from diagnosis of the primary tumour. Unfortunately, fewer than $30 \%$ of patients with CLM have primarily resectable lesions. One of the principal reasons for non-resectability is the small $\operatorname{FLRV}(4,5)$.

Today there are several options for enhancing and optimising FLRV. These include oncological treatment that aims to reduce the volume of CLM in such a way as to allow radical resection, the so-called 'downsizing' method. Other approaches include two-stage liver resection, embolization or portal vein ligation on the side of the tumour (PVE, PVL) (6). The problem with these methods in a number of patients is the failure of FLRV growth and possible progression of CLM within the liver parenchyma during the period necessary for FLRV growth, which may range from 4 to 8 weeks. Several approaches have been proposed in order to minimise this risk, some of which may prevent CLM progression, including PVE in combination with trans-arterial chemoembolization or trans-arterial radioembolization $(7,8)$, or may accelerate FLRV growth and thus significantly shorten the interval required for liver resection, e.g. PVE with application of autologous MSC, or associating liver partition and portal vein ligation for staged hepatectomy (ALPPS). 


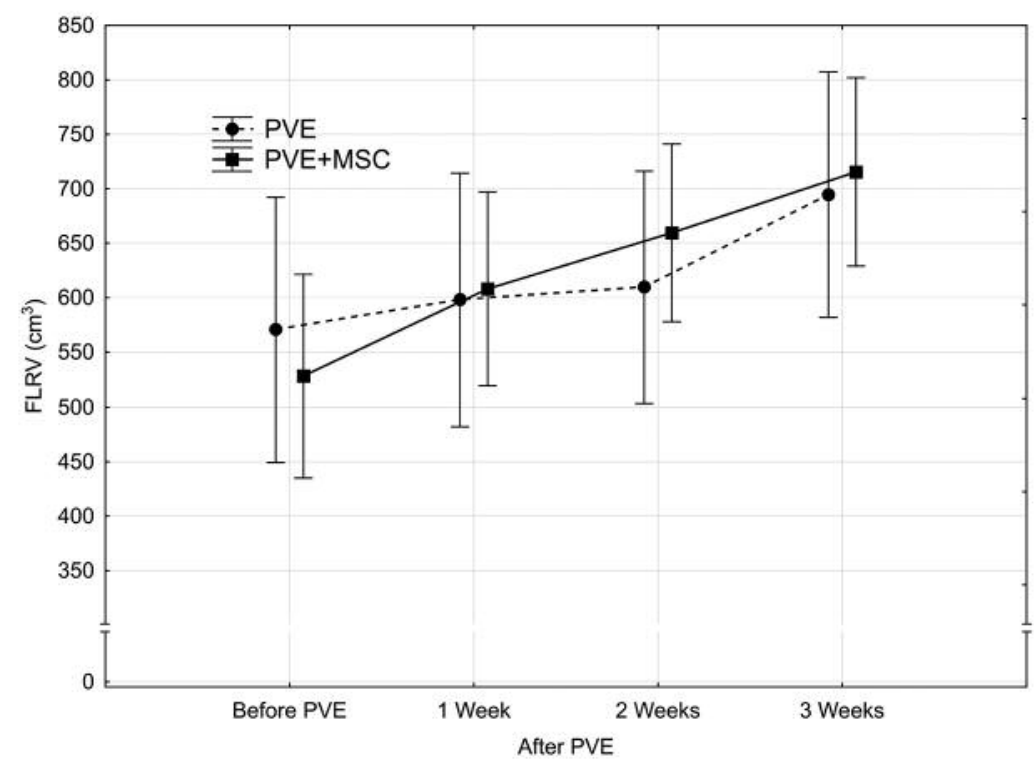

Figure 1. Comparison of computed tomographic volumometry of future liver remnant volume (FLRV) growth in the groups treated with portal vein embolization (PVE) alone and with mesenchymal stem cell transplantation (PVE-MSC).

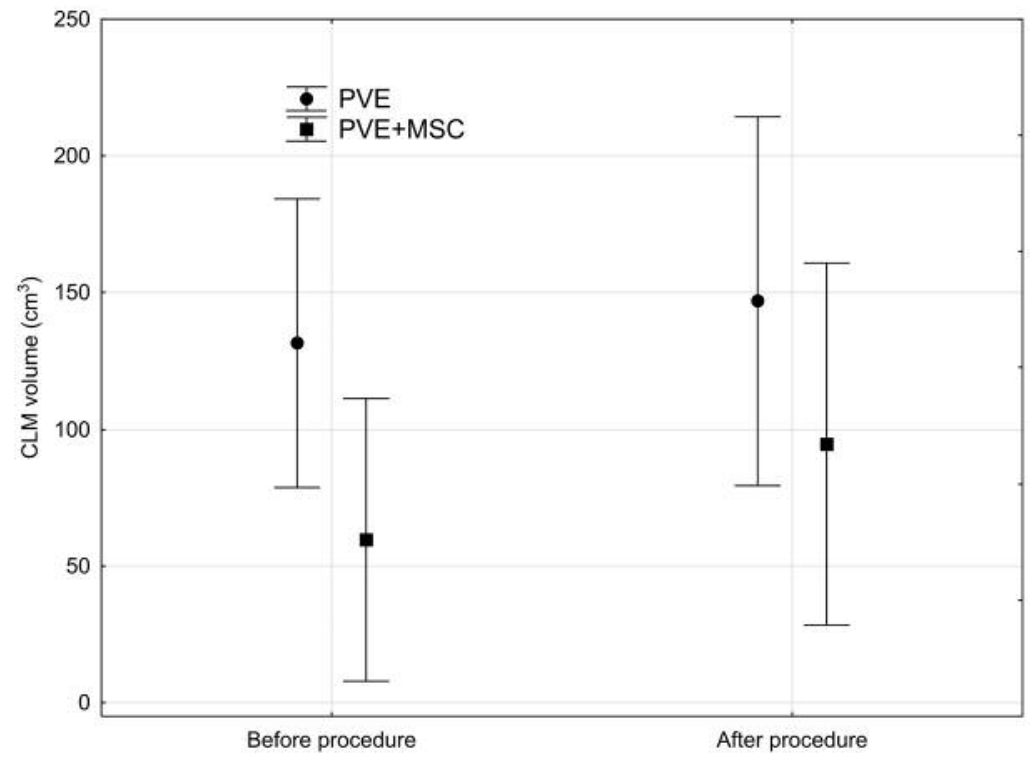

Figure 2. Comparison of growth of colorectal liver metastases (CLM) volume in in the groups treated with portal vein embolization (PVE) alone and with mesenchymal stem cell transplantation (PVE-MSC).

The general aim of these two latter methods is to increase the volume of liver tissue that remains after CLM resection so that it is sufficient for maintaining liver functions. In patients with normal liver tissue, a sufficient FLRV is considered to be a volume exceeding $25-30 \%$ of the total liver volume. In patients with damaged liver parenchyma, this volume is then great than $40 \%$. In these patients, apart from FLRV, it is also important to determine liver function using functional tests (9).

The two-stage liver resection technique is indicated in patients with bilobar CLM involvement, where the FLRV is insufficient. The first stage involves removal of the tumour 


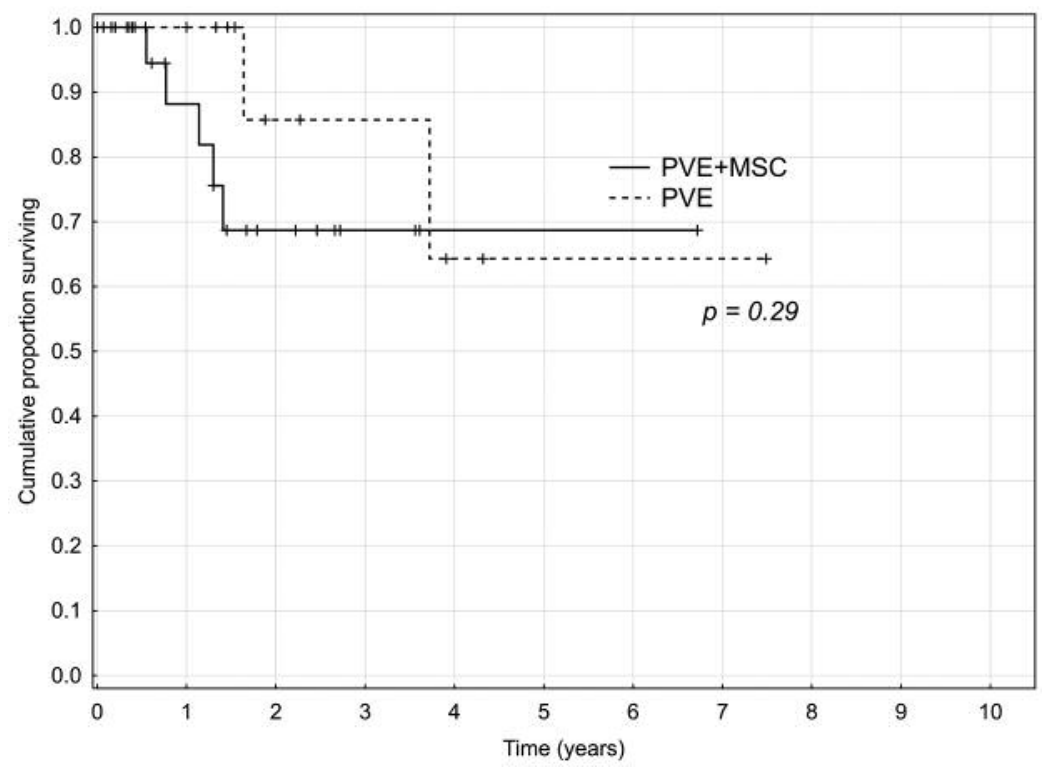

Figure 3. Overall survival in in the groups treated with portal vein embolization (PVE) alone and with mesenchymal stem cell transplantation (PVE$M S C)$.

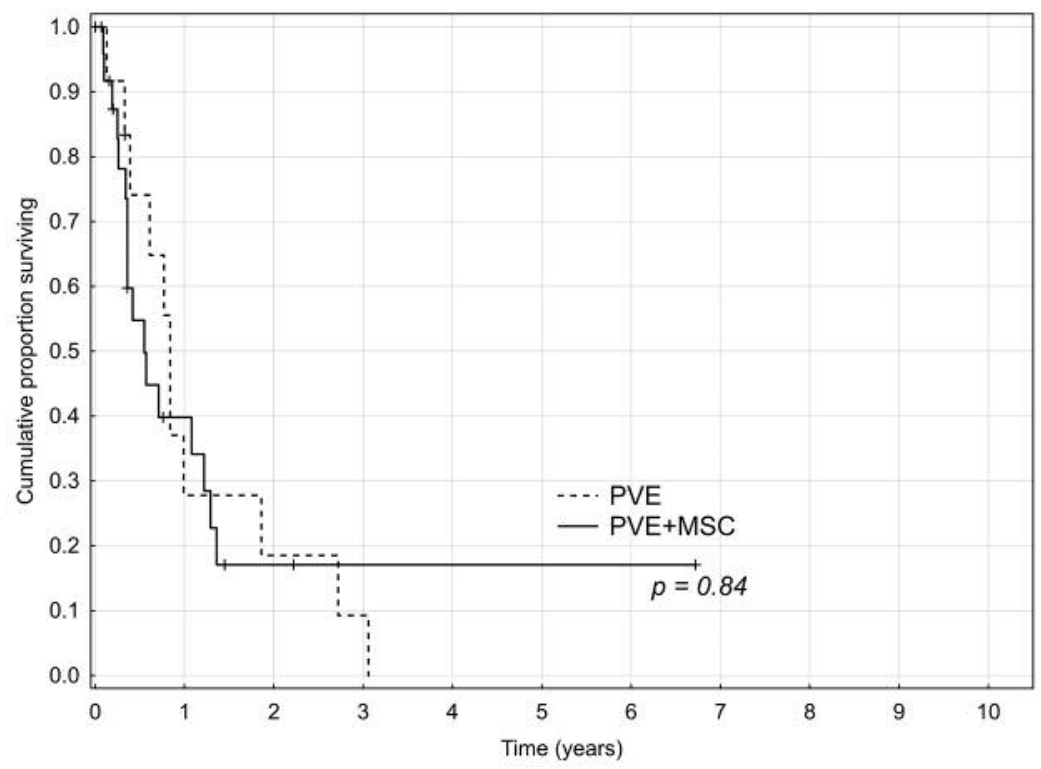

Figure 4. Progression-free survival in groups treated with portal vein embolization (PVE) alone and with mesenchymal stem cell transplantation $(P V E-M S C)$.

from one of the liver lobes and, once the remaining liver lobe has regenerated (usually after 4-8 weeks), the second liver lobe is removed. In our experience, mortality associated with two-stage liver resection is low (1-2\%) and completely comparable to that of one-stage resections. A disadvantage of this method is the relatively long interval required for optimal FLRV growth that increases the risk of further growth of liver and other extrahepatic metastases. Another problem is the development of relatively firm adhesions following the initial surgery that then complicate the secondary procedure. However, the long-term results of this method are very good and 5-year survival is above $40 \%$. Failure of two-stage resection from the aspect of sufficient FLRV growth has been described in $35 \%$ of patients. Prognostic risk factors of two- 


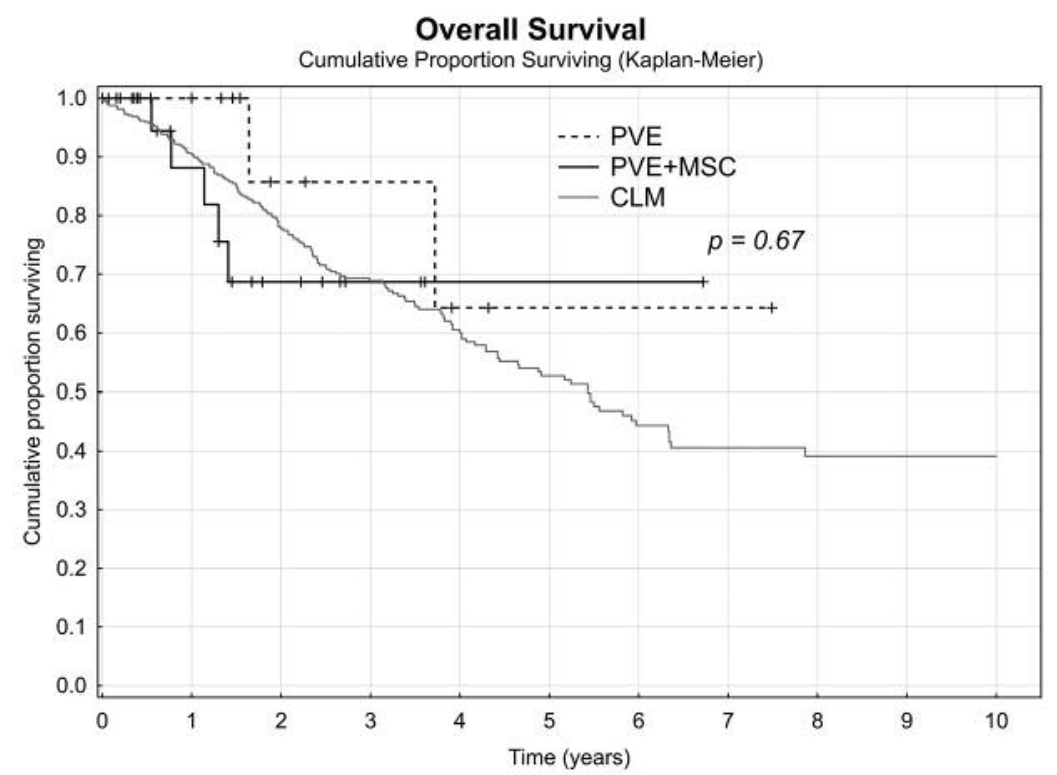

Figure 5. Comparison of overall survival between patients treated for colorectal liver metastases (CLM) with portal vein embolization (PVE) alone, $P V E$ with mesenchymal stem cell transplantation (PVE-MSC) and all patients operated on for CLM.

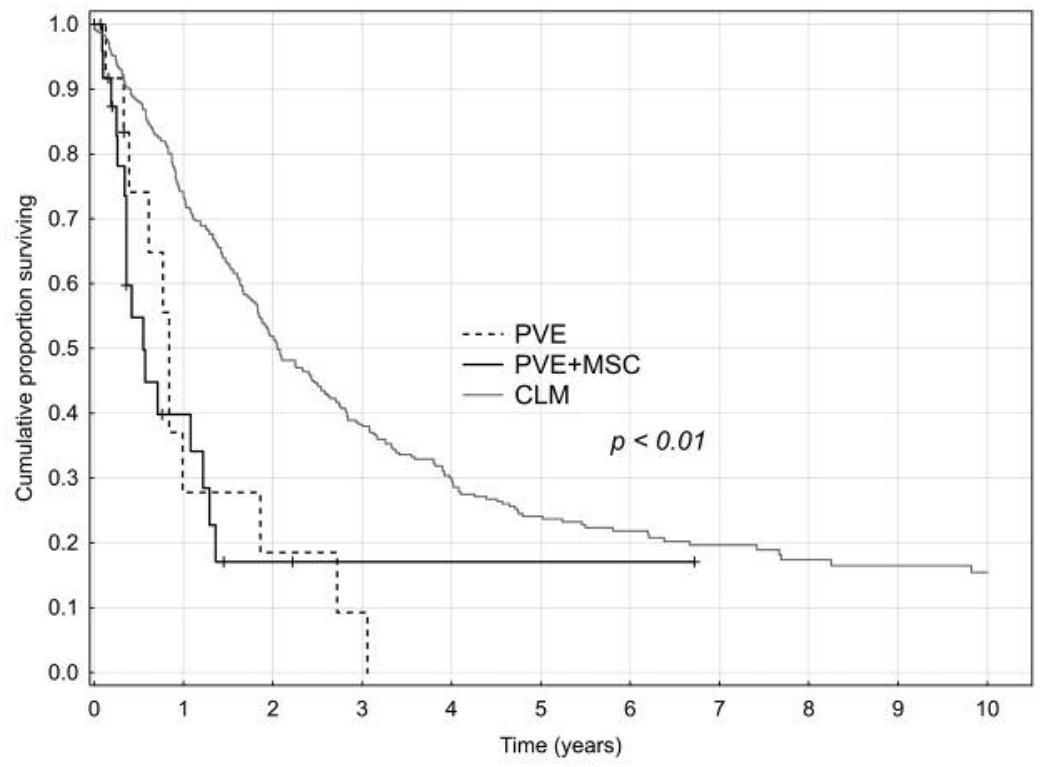

Figure 6. Comparison of progression-free survival between patients treated for colorectal liver metastases (CLM) with portal vein embolization (PVE) alone, PVE with mesenchymal stem cell transplantation (PVE-MSC) and all patients operated on for CLM.

stage resection failure include: three or more CLM in FLRV, age $\geq 70$ years, malignancy progression between the two stages, a pre-operative level of carcinoembryonic antigen $\geq 30 \mathrm{ng} / \mathrm{ml}, \geq 40 \mathrm{~mm}$ diameter of the largest CLM, and $\geq 12$ oncological treatment cycles prior to liver resection $(10,11)$.
The PVE (PVL) methods increase FLRV by $8-27 \%$ in $72-$ $80 \%$ of patients at an interval of 4-6 weeks (12). These are safe methods and their long-term results are comparable to those of primary liver resection. Liver hypertrophy may be slower in older patients as well as in the case of diabetes, 
malnutrition, infection and liver tissue damage due to toxicity. A relatively long interval of liver hypertrophy following PVE may be the cause of an increase in the size of liver or extra-hepatic metastases. One issue that has not been resolved as yet is the implementation of perioperative oncological treatment concurrently with PVE (PVL) in liver regeneration and the long-term results of subsequent liver resection.

Given the slow growth of FLRV following PVE (PVL) and the risk of CLM progression, novel methods such as ALPPS or PVE with stem cell application are being explored in order to shorten the interval necessary for FLRV hypertrophy.

ALPPS is a major ground-breaking method in liver surgery aimed at patients with primary or secondary liver tumours and insufficient FLRV $(13,14)$. This method uses a two-stage procedure with maximum shortening of the time interval between the two stages, which is essential in order to prevent tumour growth in the liver and the development of firm post-surgical adhesions in the area of the liver. It is also used in patients in whom PVE and PVL have failed as so-called 'rescue' therapy (15). A recent study described FLRV growth of $40-80 \%$ at an interval of 6-9 days after the first stage of the procedure or up to a $22 \%$ daily increment in FLVR compared to a $3 \%$ increment following PVE (16, 17). However, an enduring problem of this method is the associated high morbidity (around 35\%) and mortality (around 8\%) compared to other procedures targeting FLVR growth. Risk factors associated with postoperative complications include: age, duration of first surgical stage $\geq 5$ hours, and need for blood transfusion. The 1-and 2-year survival of patients are reported as $59 \%$ and $41 \%$, with progression-free survival at the same intervals of time of $88 \%$ and $74 \%$ (18).

PVE with MSC application attempts to increase and accelerate the regenerative capacity of the liver parenchyma and thus shorten the interval necessary for FLRV growth following PVE (18-20). In principal, this method involves PVE on the side of the tumour, MSC harvesting from the bone marrow or blood using leukapheresis and their subsequent application into the contralateral branches of the portal vein. It is presumed that the MSC accelerate liver parenchyma regeneration rate particularly via paracrine mechanisms, namely secretion of cytokines and growth factors that stimulate the growth and differentiation of hepatocytes, cholangiocytes and other cells. A major advantage compared to ALPPS is zero mortality and minimal morbidity of patients (21-26).

Since 2001, our Institution has been using staged liver resections and PVE in order to increase the secondary operability of CLM. After testing the efficacy of PVE with autologous MSC application experimentally on a pig model, we began using this method approved by the University
Hospital's Ethics Committee in clinical practice in 2010 (27). Given that no study comparing PVE versus PVE with MSC application has been published to date, we decided to compare both methods from different aspects in a set weekly interval of FLRV growth monitoring for 3 weeks. We found that there was significant FLRV growth in all patients undergoing PVE with MSC, in whom we could thus perform more $\mathrm{R} 0$ resections compared with the PVE group. The rate of CLM growth was higher in the PVE-MSC group, but the final CLM volume did not differ significantly between groups of patients following 3 weeks of monitoring. This means that in clinical practice, liver resection should be performed immediately once sufficient FLRV growth has been achieved (especially in the PVE-MSC group) thus avoiding the risk of further increase in the volume (and presumedIy in the number) of CLM. However, given that both methods stimulate proliferation and growth, the issue of potential proliferation of undetectable micrometastases in the liver and the body as a whole remains unresolved. From the aspect of long-term results of liver resection, both methods are comparable. However, earlier progression of CLM was seen in both groups compared to other patients undergoing surgery for CLM in our study. Nonetheless, even these patients with CLM recurrence may be able to undergo further resection or thermoablative procedures, thereby prolonging their survival.

The main drawback of our study is the small number of patients involved, mainly due to the inclusion criteria set for both groups. Nonetheless, we believe that PVE and PVEMSC rank among methods that significantly enhance the secondary resectability of CLM and radically prolong the survival of patients with primary non-resectable CLM. Moreover, PVE-MSC is a method that yields better results from the aspect of optimal FLRV growth, thus allowing for more secondary liver resections compared to PVE alone.

\section{Acknowledgements}

This study was supported by the Charles University Research Fund (Progres Q39).

\section{References}

1 Moris D and Pawlik TM: Personalized treatment in patients with colorectal liver metastases. J Surg Res 216: 26-29, 2017.

2 Quan D, Gallinger S, Nhan C, Auer RA, Biagi JJ, Fletcher GG, Law CH, Moulton CA, Ruo L, Wei AC and McLeod RS: The role of liver resection for colorectal cancer metastases in an era of multimodality treatment: A systematic review. Surgery 151: 860-70, 2012.

3 Treska V, Liska V, Lysak D, Mirka H, Bruha J, Duras P, Treskova I, Nahlik J, Simanek V and Topolcan O: Portal vein embolization with application of haematopoietic stem cells in patients with primarily non-resectable colorectal liver metastases. Anticancer Research 34: 7279-7286, 2014. 
4 Nagayama S, Hasegawa S, Hida K, Kawada K, Hatano E, Nakamura K, Seo S, Taura K, Yasuchika K, Matsuo T, Zaima M, Kanazawa A, Terajima H, Tada M, Adachi Y, Nishitai R, Manaka D, Yoshimura T, Doi K, Horimatsu T, Mitsuyoshi A, Yoshimura K, Niimi M, Matsumoto S, Sakai Y and Uemoto S: Multi-institutional phase II study on the feasibility of liver resection following preoperative mFOLFOX6 therapy for resectable liver metastases from colorectal cancers. Int J Clin Oncol 22: 316-323, 2017.

5 Adam R, Bhangui P, Poston G, Mirza D, Nuzzo G, Barroso E, Ijzermans J, Hubert C, Ruers T, Capussotti L, Ouellet JF, Laurent C, Cugat E, Colombo PE and Milicevic M: Is perioperative chemotherapy useful for solitary, metachronous, colorectal liver metastases? Ann Surg 252: 774-787, 2010.

6 Treska V: Methods to increase future liver remnant volume in patients with primarily unresectable colorectal liver metastases: Current state and future perspectives. Anticancer Res 36: 20652072, 2016.

7 Chapiro J, Duran R and Lin M: Early survival prediction after intra-arterial therapies: a 3D quantitative MRI assessment of tumour response after TACE or radioembolization of colorectal cancer metastases to the liver. Eur Radiol 25: 1993-2003, 2015.

8 Orwat KP, Beckham TH, Cooper SL, Ashenafi MS, Anderson MB, Guimaraes M, Yamada R and Marshall DT: Pretreatment albumin may aid in patient selection for intrahepatic Y-90 microsphere transarterial radioembolization (TARE) for malignancies of the liver. J Gastrointest Oncol 8: 1072-1078, 2017.

9 Han HS, Ahn KS, Cho JY, Yoon YS, Yoon CJ, Park KU, Min SK, Lee HK and Ryu KH: Autologous stem cell transplantation for expansion of remnant liver volume with extensive hepatectomy. Hepatogastroenterology 61: 156-61, 2014.

10 am Esch JS, Schmelzle M, Fürst G Robson SC, Krieg A, Duhme C, Tustas RY, Alexander A, Klein HM, Topp SA, Bode JG, Häussinger D, Eisenberger CF and Knoefel WT: Infusion of CD133+ bone marrow-derived stem cells after selective portal vein embolization enhances functional hepatic reserves after extended right hepatectomy: A retrospective single-center study. Ann Surg 255: 79-85, 2014.

11 Araujo RLC, Riechelmann RP and Fong Y: Patient selection for the surgical treatment of resectable colorectal liver metastases. J: Surg. Oncol 115: 213-220, 2017.

12 Pulitano C, Crawford M, Joseph D, Aldrighetti L and Sandroussi C: Preoperative assessment of postoperative liver function: The importance of residual liver volume. J Surg Oncol 110: 445-450, 2014.

13 Schadde E, Ardiles V, Slankamenac K, Tschuor C, Sergeant G, Amacker N, Baumgart J, Croome K, Hernandez-Alejandro R, Lang H, de Santibaňes E and Clavien PA: ALPPS offers a better chance of complete resection in patients with primarily unresectable liver tumors compared with conventional-staged hepatectomies: Results of a multicenter analysis. World J Surg 38: 1510-1519, 2014

14 de Santibañes E, Alvarez FA, Ardiles V, Pekolj J and de Santibañes M: Inverting the ALPPS paradigm by minimizing first stage impact: The mini-ALPPS technique. Langenbecks Arch Surg 401: 557-563, 2016.

15 Torzilli G, Adam R, Viganò L, Imai K, Goransky J, Fontana A, Toso C, Majno P and de Santibañes E: Surgery of colorectal liver metastases: pushing the limits. Liver Cancer 6: 80-89, 2016.
16 Chapelle T, Op de Beeck B, Roeyen G, Bracke B, Hartman V, De Greef K, Huyghe I, Van der Zijden T, Morrison S, Francque $\mathrm{S}$ and Ysebaert D: Measuring future liver remnant function prior to hepatectomy may guide the indication for portal vein occlusion and avoid posthepatectomy liver failure: A prospective interventional study. HPB 19: 108-117, 2017.

17 Imai K, Castro Benitez C, Allard MA, Vibert E, Sa Cunha A, Cherqui D, Castaing D, Bismuth H, Baba H and Adam R: Potential of a cure in patients with colorectal liver metastases and concomitant extrahepatic disease. J Surg Oncol 115: 488-496, 2017.

18 Simoneau E, Aljiffry M, Salman A, Abualhassan N, Cabrera T, Valenti D, El Baage A, Jamal M, Kavan P, Al-Abbad S, Chaudhury P, Hassanain $M$ and Metrakos P: Portal vein embolization stimulates tumour growth in patients with colorectal cancer liver metastases. HPB 14(7): 461-468, 2012.

19 Russolillo N, Ratti F, Viganò L, Langella S, Cipriani F, Aldrighetti $\mathrm{L}$ and Ferrero A: The influence of aging on hepatic regeneration and early outcome after portal vein occlusion: A case-control study. Ann Surg Oncol 22: 4046-4051, 2015.

20 Canepa MC, Quaretti P, Perotti C, Vercelli A, Rademacher J, Peloso A, Barbieri L, Franchi E, Briani L, Gaspari A, Brugnatelli S, Pedrazzoli P, Dionigi P and Maestri: Autologous CD133+ cells augment the effect of portal embolization. Minerva Chir 68: 163-168, 2013.

21 Fürst G, Schulte am Esch J, Poll LW, Hosch SB, Fritz LB, Klein M, Godehardt E, Krieg A, Wecker B, Stoldt V, Stockschläder M, Eisenberger CF, Mödder $U$ and Knoefel WT: Portal vein embolization and autologous CD133+ bone marrow stem cells for liver regeneration: Initial experience. Radiology 243: 171-179, 2007.

22 Kuo SC, Azimi-Tabrizi A and Briggs G, Maher R, Harrington T, Samra JS, Drummond M and Hugh TJ: Portal vein embolization prior to major liver resection. ANZ J Surg 84: 341-345, 2014.

23 Stavrou GA, Donati M, Fard-Aghaie MH and Zeile M, Huber TM, Stang A and Oldhafer KJ: Did the international ALPPS meeting 2015 have an impact on daily practice? The Hamburg Barmbek experience of 58 cases. Visc Med 33:456-461, 2017.

24 Schlitt HJ, Hackl C and Lang SA: 'In-situ split' liver resection/ALPPS - historical development and current practice. Visc Med 33: 408-412, 2017.

25 Choi YI, Moon HH and Shin DH: Two cases of ALPPS procedure: simultaneous ALPPS and colorectal resection and ALPPS procedure for hepatic malignancy larger than 15 centimeter. Ann Hepatobiliary Pancreat Surg 21: 151-156, 2017.

26 Maulat C, Suc B and Muscari F: Rescue ALPPS after portal embolization for colorectal metastases. J Visc Surg 155: 77-78, 2018.

27 Enne M, Schadde E, Björnsson B, Hernandez Alejandro R, Steinbruck K, Viana E, Robles Campos R, Malago M, Clavien PA, De Santibanes E and Gayet B: ALPPS as a salvage procedure after insufficient future liver remnant hypertrophy following portal vein occlusion. HPB 19: 1126-1129, 2017.

28 Ludvik J, Duras P, Treska V, Matouskova T, Bruha J, Fichtl J, Lysak D, Ferda J and Baxa J: Portal vein embolization with contralateral application of stem cells facilitates increase of future liver remnant volume in patients with liver metastases. Cardiovasc Intervent Radiol 40: 690-696, 2017.

Received June 24, 2018

Revised July 15, 2018

Accepted July 19, 2018 